\title{
Role of L-DOPA in Spinal Nociceptive Reflex Activity: Higher Sensitivity of A $\delta$ Versus C Fibre-Evoked Nociceptive Reflexes to L-DOPA
}

\author{
E. D. SCHOMBURG ${ }^{1}$, P. DIBAJ ${ }^{2}$, H. STEFFENS ${ }^{1}$ \\ ${ }^{1}$ Institute of Physiology, University of Göttingen, Göttingen, Germany, ${ }^{2}$ Max-Planck-Institute for \\ Experimental Medicine, Department of Neurogenetics, Göttingen, Germany
}

Received October 21, 2010

Accepted March 25, 2011

On-line May 16, 2011

\begin{abstract}
Summary
The role of L-DOPA in spinal nociceptive reflex activity has been re-evaluated. In high spinal cats, with supraspinal loops being excluded, the onset of reflex facilitation induced by noxious radiant heat is delayed after injection of L-DOPA by 4 to 10 s, i.e. the early component of nociceptive reflex facilitation is blocked, while the late component persisted. Further investigations have shown that the early component of reflex facilitation induced by noxious radiant heat is mediated by $A \bar{\delta}$-fibres and the late component by $\mathrm{C}$-fibres. Therefore, it can be assumed that L-DOPA, like opioids, preferentially blocks the transmission in nociceptive reflex pathways from $A \delta$-fibres.
\end{abstract}

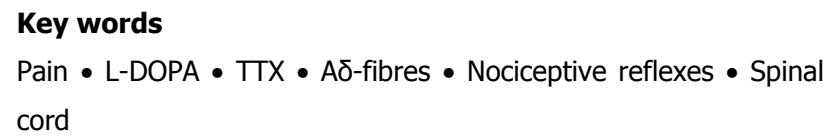

\section{Corresponding author}

E. D. Schomburg, Institute of Physiology, University of Göttingen, Humboldtallee 23, D-37073 Göttingen, Germany. Fax: +49-551395923. E-mail: eschomb@gwdg.de

In the beginning, the relation of L-DOPA to spinal nociceptive reflex activity has not been clearly defined. When Eccles and Lundberg (1959) introduced the term "flexor reflex afferents" (FRA, a term which is "really a misnomer", quoting Lundberg 1979, but without a better alternative) for "afferents which may evoke the flexion reflex" (within the title of the publication), they comprised low to medium threshold cutaneous afferents, joint afferents and medium to high threshold muscle afferents under this term but originally not nociceptive afferents (Lundberg 1982). Indeed, a contribution of nociceptive afferents to the quite unspecific FRA system was shown some time later by demonstrating a convergence from nociceptive cutaneous afferents onto common interneurones of non-nociceptive FRA (Steffens and Schomburg 1993). Furthermore, another characteristic of FRA also applies to nociceptive afferents, namely, that early polysynaptic spinal reflex pathways from these afferents are depressed by intravenous injection of L-DOPA (Andén et al. 1966, Lundberg 1982, Schomburg and Steffens 1998) with the exception of the excitatory nociceptive pathway from the foot pad to plantaris and intrinsic foot extensors (Schomburg and Steffens 1998).

A further evaluation of the influence of L-DOPA on spinal nociceptive reflexes was performed in nine experiments with anaemically decapitated, high spinal cats, excluding supra-spinal influence and loops (for further technical details see Kniffki et al. 1981 and Schomburg and Steffens 1998). These experiments have shown that the facilitation during the early period of noxious heat application is more readily suppressed by L-DOPA than the facilitation during the later period. This is shown in Figure $1 \mathrm{~A}$ which is taken with modification from Schomburg and Steffens (1998). In the control before L-DOPA application the monosynaptic test reflex (reflex interval $2 \mathrm{~s}$ ) from the posterior biceps 
semitendinosus (PBSt) muscle started to increase in parallel with the background noise within $2 \mathrm{~s}$ after the onset of the conditioning noxious radiant heat stimulation $\left(52{ }^{\circ} \mathrm{C}\right.$, lower traces in Fig. $1 \mathrm{~A}$ and $\left.\mathrm{B}\right)$ at the central foot pad. After injection of L-DOPA (Fig. $1 \mathrm{~B}, 80 \mathrm{~min}$ after the i. v. injection of $100 \mathrm{mg} \mathrm{L-DOPA} / \mathrm{kg}$ bodyweight) the PBSt test reflex and the background noise started to increase about $10 \mathrm{~s}$ after the onset of radiant heat (Fig. 1B).

\section{PBSt-MR conditioning with noxious heat (pad)}

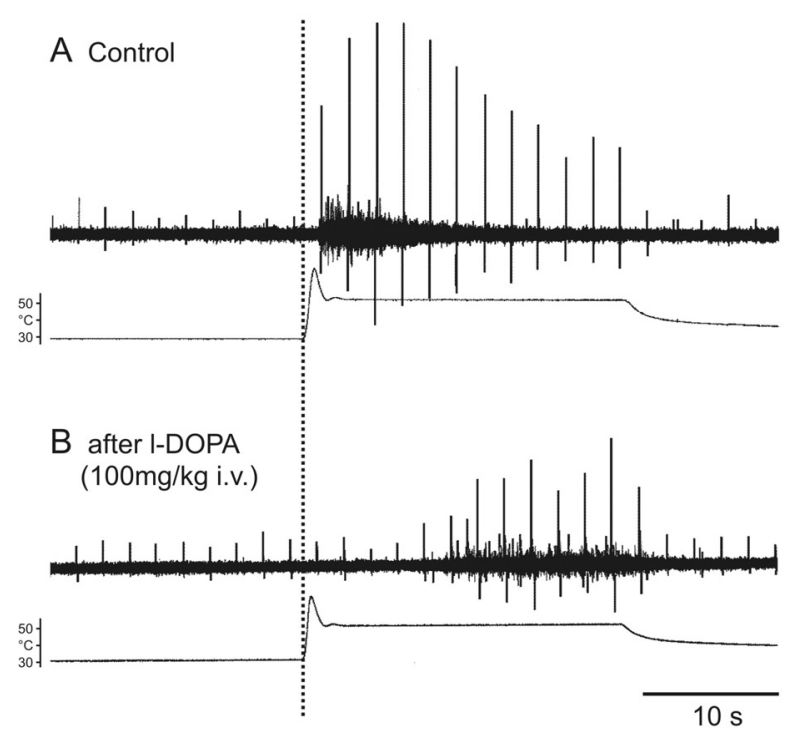

Fig. 1. Depression of the early component of noxious heat induced facilitation of the monosynaptic reflex of PBSt by L-DOPA. (A) control, (B) $80 \mathrm{~min}$ after L-DOPA (100 mg/kg i. v.). Anaemically decapitated, high spinalised cat; monosynaptic reflexes evoked by electrical stimulation of the PBSt nerve (stimulus strength 5 times threshold) recorded from ventral roots L7/S1; noxious radiant heat $\left(52^{\circ} \mathrm{C}\right)$ applied to the central pad of the foot (lower traces in A and B). Modified from Schomburg and Steffens (1998).

The observed increase of the delay between the onset of noxious radiant heat and reflex facilitation from less than $2 \mathrm{~s}$ before the injection of L-DOPA to 4 to $10 \mathrm{~s}$ after the injection of L-DOPA in different experiments is much to long to be ascribed to the well-known release of the long latency FRA pathways by L-DOPA. The activation of these L-DOPA induced long latency FRA pathways, which emerge together with the blockade of the short latency FRA pathways, occurs with a latency of some 100 to $200 \mathrm{~ms}$ (Andén et al. 1966).

Originally, the observed phenomenon of an increased time lag of nociceptive reflex facilitation after L-DOPA was just interpreted as an increase of the delay of the reflex action of noxious radiant heat (Schomburg and
Steffens 1998). However, results of subsequent experiments with a blockade of A $\delta$-fibres by TTX now allow another interpretation. After local application of TTX at the afferent nerve (tibial nerve from the foot sole), which leads to a block of the conduction in A $\delta$-fibres but leaves conduction in TTX resistant C-fibres intact (Schomburg et al. 2000, 2011, Kimura and Kontani 2008), the latency of the conditioning effect of noxious radiant heat onto monosynaptic test reflexes of hindlimb muscles increased by around $5 \pm 2 \mathrm{~s}$ (Schomburg et al. 2000). This is in the same range as the increase of the delay of reflex facilitation observed after application of L-DOPA and after application of opioids (Schomburg et al. 2011). Therefore, it can be assumed that L-DOPA, like opioids, blocks the transmission in nociceptive reflex pathways from A $\delta$ fibreafferents more readily than in those from $\mathrm{C}$ fibre-afferents. When the sensitivity to L-DOPA is taken as a criterion for the attribution of a pathway to the FRA system (Andén et al. 1966, Lundberg 1982, Schomburg 1990), mainly the nociceptive A $\delta$-afferents seem to be related to the FRA system.

Interestingly, nonmotor symptoms of patients with Parkinson disease including pain or aching also respond to dopaminergic treatment (Stacy et al. 2010). Furthermore, dopaminergic treatment appears to improve chronic pain symptoms in patients with fibromyalgia (Holman and Myers 2005). With regard to the antinociceptive mechanism of L-DOPA, the dopamine $\mathrm{D}_{2}$ receptor in the brain seems to have a crucial role in pain modulation (Hagelberg et al. 2002). In addition, experiments with intrathecal co-administration of substance $\mathrm{P}$ and L-DOPA confirm the crucial role of the $\mathrm{D}_{2}$ receptor in attenuating pain transmission at the spinal level (Shimizu et al. 2004). The spinal anti-nociceptive influence of L-DOPA has been confirmed by recent electrophysiological studies on substantia gelatinosa neurones which revealed inhibitory effects by $\mathrm{D}_{2}$-like receptors in the rat spinal cord (Tamae et al. 2005).

The experiments were performed according to the ethical guidelines of the national animal protection law and were authorised by the ethical committee of the University of Göttingen.

\section{Conflict of Interest}

There is no conflict of interest.

\section{Acknowledgements}

This work was supported by a grant of the Deutsche Forschungsgemeinschaft (SCHO 37/16). 


\section{Abreviations}

L-DOPA, L-3,4-Dihydroxyphenylalanin; FRA, flexor reflex afferents; PBSt, posterior biceps semitendinosus; Pl, plantaris; TTX, tetrodotoxin

\section{References}

ANDÉN NE, JUKES MGM, LUNDBERG A, VYKLICKÝ L: The effect of DOPA on the spinal cord. 1. Influence on transmission from primary afferents. Acta Physiol Scand 67: 373-386, 1966.

ECCLES RM, LUNDBERG A: Synaptic actions in motoneurones by afferents which may evoke the flexion reflex. Arch Ital Biol 97: 199-221, 1959.

HAGELBERG N, MARTIKAINEN IK, MANSIKKA H, HINKKA S, NAGREN K, HIETALA J, SCHEININ H, PERTOVAARA A: Dopamine D2 receptor binding in the human brain is associated with the response to painful stimulation and pain modulatory capacity. Pain 99: 273-279, 2002.

HOLMAN AJ, MYERS RR: A randomized, double-blind, placebo-controlled trial of pramipexole, a dopamine agonist, in patients with fibromyalgia receiving concomitant medications. Arthritis Rheum 52: 2495-2505, 2005.

KIMURA S, KONTANI H: Separate recording of A-delta and C fiber-mediated nociceptive flexor reflex responses of mouse hindlimb using electromyography and the characteristics of wind-up appearing in the responses. J Pharmacol Sci 108: 172-178, 2008.

KNIFFKI KD, SCHOMBURG ED, STEFFENS H: Effects form fine muscle and cutaneous afferents on spinal locomotion in cats. $J$ Physiol Lond 319: 543-554, 1981.

LUNDBERG A: Multisensorial control of spinal reflex pathways. Prog Brain Res 50: 11-28, 1979.

LUNDBERG A: Inhibitory control from the brain stem of transmission from primary afferents to motoneurones, primary afferent terminals and ascending pathways. In: Brain Stem Control of Spinal Mechanisms. B SJÖLUND, A BJÖRKLUND (eds), Elsevier, Amsterdam, 1982, pp 179-224.

SCHOMBURG ED: Spinal sensorimotor systems and their supraspinal control. Neurosci Res 7: 265-340, 1990.

SCHOMBURG ED, DIBAJ P, STEFFENS H: Differentiation between A $\delta$ and $\mathrm{C}$ fibre evoked nociceptive reflexes by TTX resistance and opioid sensitivity in the cat. Neurosci Res 69: 241-245, 2011.

SCHOMBURG ED, STEFFENS H: Comparative analysis of L-DOPA actions on nociceptive and non-nociceptive spinal reflex pathways in the cat. Neurosci Res 31: 307-316, 1998.

SCHOMBURG ED, STEFFENS H, MENSE S: Contribution of TTX-resistant C-fibres and A $\delta$-fibres to nociceptive flexor-reflex and non-flexor-reflex pathways in cats. Neurosci Res 37: 277-287, 2000.

SHIMIZU T, IWATA S, MORIOKA H, MASUYAMA T, FUKUDA T, NOMOTO M: Antinociceptive mechanism of L-DOPA. Pain 110: 246-249, 2004.

STACY MA, MURCK H, KROENKE K: Responsiveness of motor and nonmotor symptoms of Parkinson disease to dopaminergic therapy. Prog Neuropsychopharmacol Biol Psychiatry 34: 57-61, 2010.

STEFFENS H, SCHOMBURG ED: Convergence in segmental reflex pathways from nociceptive and non-nociceptive afferents to $\alpha$-motoneurones in the cat. J Physiol Lond 466: 191-211, 1993.

TAMAE A, NAKATSUKA T, KOGA K, KATO G, FURUE H, KATAFUCHI T, YOSHIMURA M: Direct inhibition of substantia gelatinosa neurones in the rat spinal cord by activation of dopamine D2-like receptors. $J$ Physiol Lond 568: 243-253, 2005. 